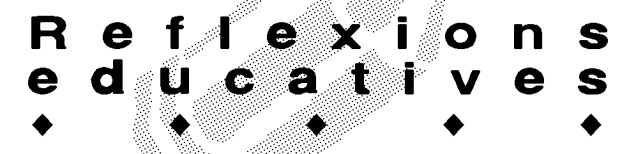

\title{
Proposta de seqüenciació didàctica en relació a les aportacions de l'àrea d'educació física a la competència comunicativa lingüística i audiovisual
}

\author{
Dolors Cañabate Ortíz. Facultat d'Educació i Psicologia \\ Universitat de Girona
}

\begin{abstract}
Resum
El present article recull reflexions i propostes sobre les aportacions que ofereix l'àrea d'educació física al desenvolupament de la competència comunicativa, amb l'objectiu de col-laborar activament a millorar-la. Des d'aquest compromís, en primer Iloc, s'indiquen les capacitats relacionades amb la competència comunicativa i, posteriorment, es relacionen aquestes capacitats des de l'especificitat de les situacions d'aprenentatge que aporta l'àrea d'educació física.
\end{abstract}

Paraules clau: programació didàctica, educació física, competència comunicativa, llenguatge corporal, habilitats.

\section{Introducció}

La importància de la comunicació en el procés educatiu ha estat objecte d'atenció preferent en els darrers anys. Des d'un plantejament que entengui el coneixement com una representació - més que no pas com una veritat absoluta-, prenen una innegable rellevància en el procés d'aprenentatge les diverses formes de comunicació implicades en la tasca de representar-nos el món. La transmissió del coneixement no pot funcionar, a l'escola d'avui, com a imposició en vertical de sabers, sinó com a resultat d'una construcció conjunta que implica professors i alumnes. Com han destacat Edward i M ercer
(1998), el desenvolupament de l'activitat diària a l'aula és el procés a través del qual professors i alumnes van creant i desenvolupant contextos mentals compartits, formes comunes de conceptualitzar els materials, els continguts i, en general, tots els elements del procés educatiu.

La competència comunicativa apareix, a més, com a fonamentació necessària per a l'adquisició d'altres competències bàsiques. La competència comunicativa esdevé una competència clau per a l'aprenentatge, que es va desenvolupant i matisant en totes i cadascuna de les activitats educatives proposades. Comunicar, per tant, és fonamental per a la comprensió significativa de les informacions i la construcció de coneixements cada vegada més complexos.

Cal tenir en compte que la competència comunicativa és una competència bàsica per a l'alumnat, en el sentit més alfabetitzador i cultural.

"L'escola encara està basada en el llenguatge i l'escriptura, com si l'accés a la cultura avui fos de via única, i la veritat és que s'ha vist que l'accés a la informació i a la cultura arriba per una gran quantitat de vies. És possible que la via de l'escriptura sigui una via més i no gaire important. (...) Caldria que les institucions educatives fessin un gran esforç en el sentit de formar cada cop millor en comunicació els ensenyants, en tècniques que permetin de processar 


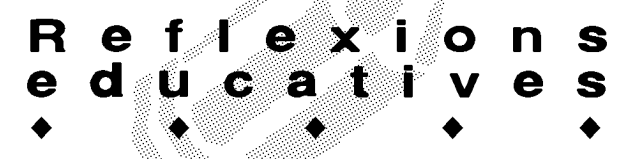

la informació. I en general, en tècniques que permetin de processar la informació rebuda a través de tots i cada un dels nostres sentits. Cal invertir en comunicació... sempre dic que la inversió més gran que ha fet la naturalesa en tot el llarg viatge a través de l'evolució ha estat, sense cap mena de dubte, la inversió en comunicació." (Serrano 1996, p.34).

La competència comunicativa no solament es refereix a incloure un tipus de comunicació - la verbal, incloent-hi la parla i l'escriptura-, sinó que ha d'incloure també la comunicació no verbal, la comunicació corporal (de la mímica i del gest), el llenguatge musical, artístic i cultural. L'educació física és també educació en comunicació.

L'acció motriu la podem considerar com l'eix bàsic de l'acció educativa, es desenvolupa a través de les activitats de la vida quotidiana, on el cos és imprescindible. Aspectes com el posat, el gest, la mirada, l'expressió corporal o la motricitat són bàsics per al desenvolupament i la comunicació de la persona.

"Al llarg de l'existència, el cos esdevé una part fonamental de la nostra identitat; és el suport de la vida, és el qui escolta, el qui parla, el qui escriu, el qui canta, el qui mira, el qui pinta, el qui pensa, el qui gesticula, el qui corre, el qui dansa, el qui juga, el qui expressa... Constitueix en si mateix un mitjà de representació i comunicació expressiva. El llenguatge corporal és present en totes les activitats. És la base per a la interpretació musical, la creació artística, el teatre, l'expressió... Cal un treball educatiu específic que atengui totes les formes possibles d'interacció motriu i que possibiliti les seves relacions. Això es podrà fer a través de diferents tipus de pràctiques motrius: jocs motors, esports, pràctiques motrius d'expressió, jocs i esports tradicionals, balls i danses". (Pacte Nacional per a l'Educació. Debat curricular, 2003, p. 118).

L'educació física pot i ha de promoure aprenentatges rellevants que cap altra assignatura pot ser capaç de realçar, tant en l'àmbit personal com social.

"La finalitat de l'educació física és preparar els nens i els joves per una participació gratificant en la cultura del moviment al llarg de tota la vida, dedicant també especial atenció a la promoció i adquisició d'estils de vida actius i saludables". (Carreiro, 2009, p. 8).
L'educació física pretén el desenvolupament de la persona en la seva globalitat, fet que implica aspectes motrius, cognitius, afectius i socials. Sota aquesta perspectiva, té molt per aportar a les competències bàsiques del currículum. En aquest cas, a la competència comunicativa.

\section{Marc teòric}

La importància que han adquirit les competències comunicatives en els nous currículums d'educació primària i secundària es justifiquen per raons que no són únicament estratègiques o metodològiques, sinó que tenen també un abast de caràcter epistemològic.

Sobre l'escola recau la responsabilitat d'iniciar de forma efectiva els nens i nenes en diversos llenguatges que són vehicle d'expressió i comprensió de les diverses formes de coneixement que tenim al nostre abast. Els nous currículums destaquen de manera prou clara la importància de la competència comunicativa:

"Aprendre és una activitat social, i saber comunicar esdevé una competència clau per a l'aprenentatge, que es va desenvolupant i matisant en totes i cadascuna de les activitats educatives. Comunicar, per tant, és fonamental per a la comprensió significativa de les informacions i la construcció de coneixements cada vegada més complexos."

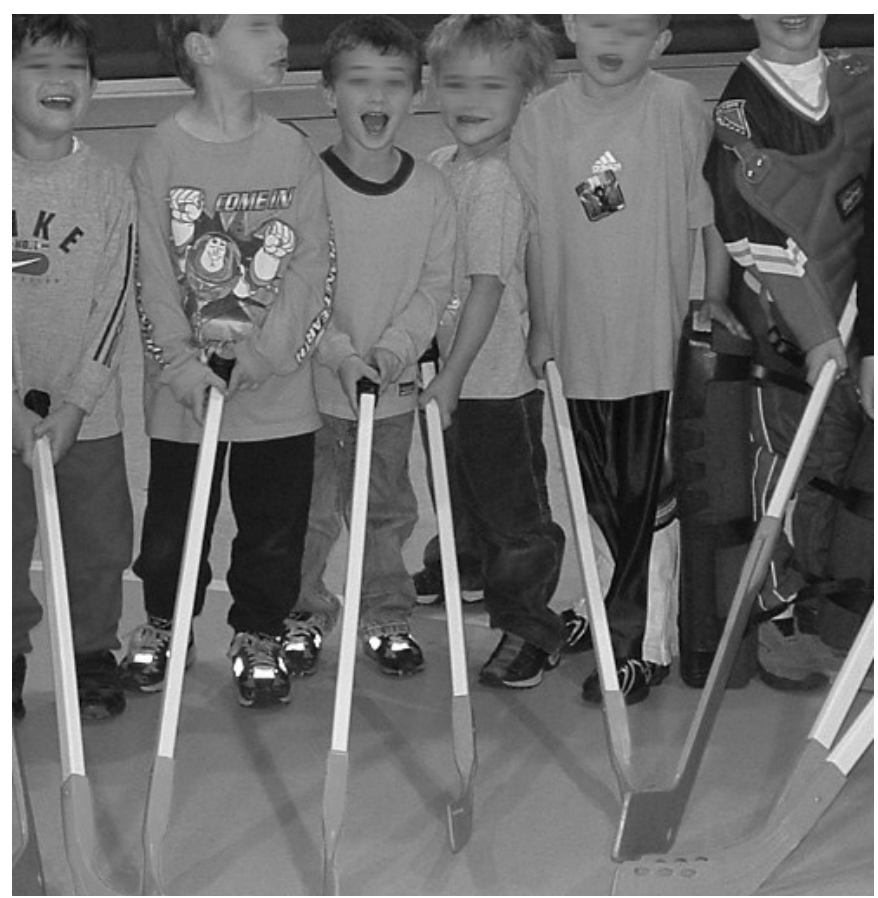




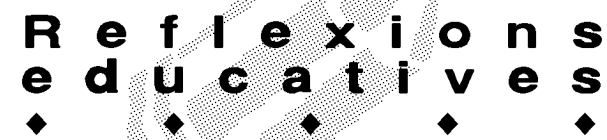

La competència comunicativa apareix, a més, com a fonamentació necessària per a l'adquisició d'altres competències bàsiques: les metodològiques de la cerca i gestió de la informació, treballar de manera cooperativa i ser conscient dels propis aprenentatges, interpretar la realitat i habitar el món i conviure. En definitiva, afavoreix la construcció del coneixement i el desenvolupament del pensament propi i de la pròpia identitat.

Aprendre a comunicar vol dir saber expressar fets, conceptes, emocions, sentiments i idees. És fonamental I'habilitat per expressar, argumentar i interpretar pensaments, sentiments i fets, i l'habilitat d'interactuar de manera adequada en contextos socials i culturals diversos. En la comunicació s'interpreta de forma significativa la informació que es rep i, fent servir els processos cognitius adequats, es desenvolupa la capacitat per generar informació amb noves idees, saber-les combinar amb altres, i avaluar la informació rebuda més enllà del seu significat. Aprendre a comunicar també és saber utilitzar diferents llenguatges i tecnologies de la informació i la comunicació.

Les competències es poden aprendre, però no ensenyar de forma directa. Les competències són un referent per l'acció educativa, però cal tenir en compte que tant les competències com les capacitats no són directament avaluables. El sistema educatiu ha de facilitar centrar els aprenentatges de valors, actituds, habilitats i coneixements específics.

El concepte de competència posa l'accent en el fer i el saber fer, és a dir, en la mobilització o aplicació del coneixement, marcant d'aquesta manera la importància de la funcionalitat dels aprenentatges escolars. No és suficient adquirir uns coneixements: cal utilitzar-los quan la situació ho requereixi (Coll, 2008).

\section{Objectius}

L'objectiu general d'aquest article és presentar una proposta de les aportacions que l'educació física pot aportar al desenvolupament de la competència comunicativa.

La concreció d'aquest objectiu requereix:

-Revisió bibliogràfica

- Concreció de les capacitats en relació amb la competència comunicativa

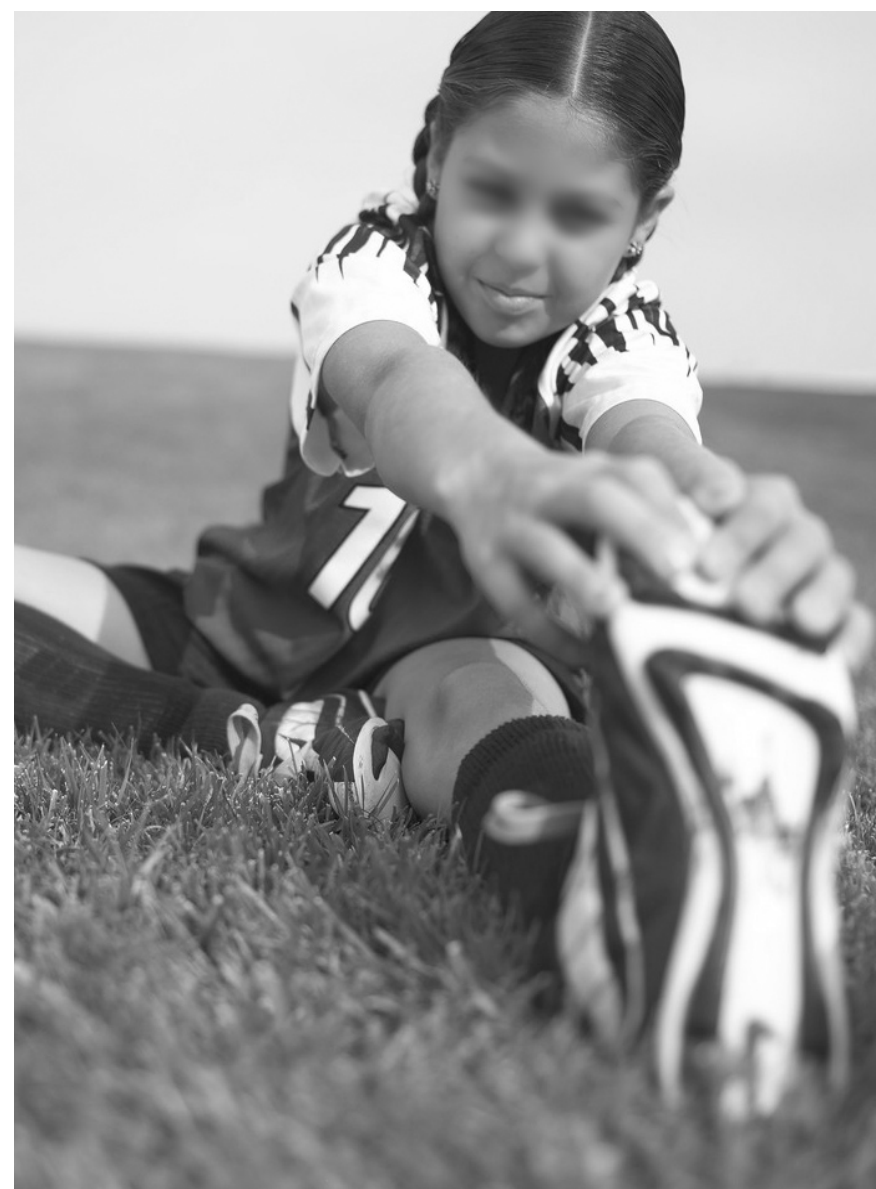

- Relació de capacitats i habilitats d'aprenentatge en relació amb la competència

- Concreció de les aportacions de l'àrea d'Educació Física

Som conscients que tots els plantejaments teòrics depenen de com s'apliquen a la pràctica. És aquí on aquest article vol participar aportant elements que facilitin el procés d'ensenyament i aprenentatge de les competències. Pensem que contribuir a identificar capacitats i habilitats, així com les aportacions de l'àrea, ens ajudarà a dur a terme la programació didàctica, que ha de respondre a la qüestió "Al final de la unitat didàctica l'alumnat ha de ser competent per..."

\section{Disseny metodològic}

Ens situem en el camp de les didàctiques de les disciplines, les didàctiques específiques que valoren l'especificitat de les situacions d'aprenentatge que es desenvolupen segons els continguts, els objectius per ensenyar/aprendre i les característiques particulars dels alumnes i dels mestres. 


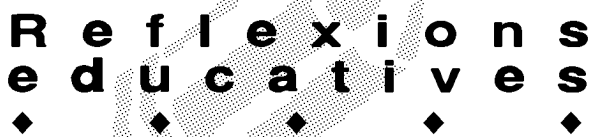

És un camp d'estudi i d'acció que té molt per aportar a la millora educativa precisament per la seva visió enfocada en allò particular i específic.

L'anàlisi en profunditat d'aquest cas en particular no pretén generalitzar resultats, però ha de permetre generar hipòtesis i prendre decisions respecte a la millora del cas (Latorre, del Rincón, Arnal, 1996), així com oferir un enfocament que faciliti el plantejament de les unitats didàctiques des de l'àrea d'Educació Física amb relació al desenvolupament de les competències bàsiques. La metodologia requereix la definició d'un tema, un cas i un enfocament d'estudi (Stake, 1999).

-Tema: Aportacions de l'educació física a la competència comunicativa

-Cas: La programació en competències des de l'àrea d'Educació Física en relació als principis pedagògics de la LOE

-Focus d'estudi: Seqüenciació didàctica per competències

En primer Iloc, s'han concretat algunes de les capacitats que es troben en relació amb la competència comunicativa lingüística i audiovisual. En segon lloc, hem seguit avançant en la nostra concreció i hem relacionat les capacitats amb les habilitats, i l'última part de l'article la dediquem a la presentació d'algunes de las aportacions que l'àrea d'Educació Física pot oferir a la competència comunicativa lingüística i audiovisual.

\section{Resultats i discussió}

En primer lloc ens plantegem què han de millorar els nostres alumnes de primària per desenvolupar la competència comunicativa lingüística i audiovisual, i quines són les situacions $i$ experiències que facilitaran la presa de decisions (Freire, 1998).

A continuació donem a conèixer la relació de les capacitats i habilitats d'acord amb la competència comunicativa lingüística i audiovisual. Aquesta relació no pretén ser una proposta tancada i única, sinó donar possibilitats a la gran oferta que n'ofereix la competència per desenvolupar (taula 1).

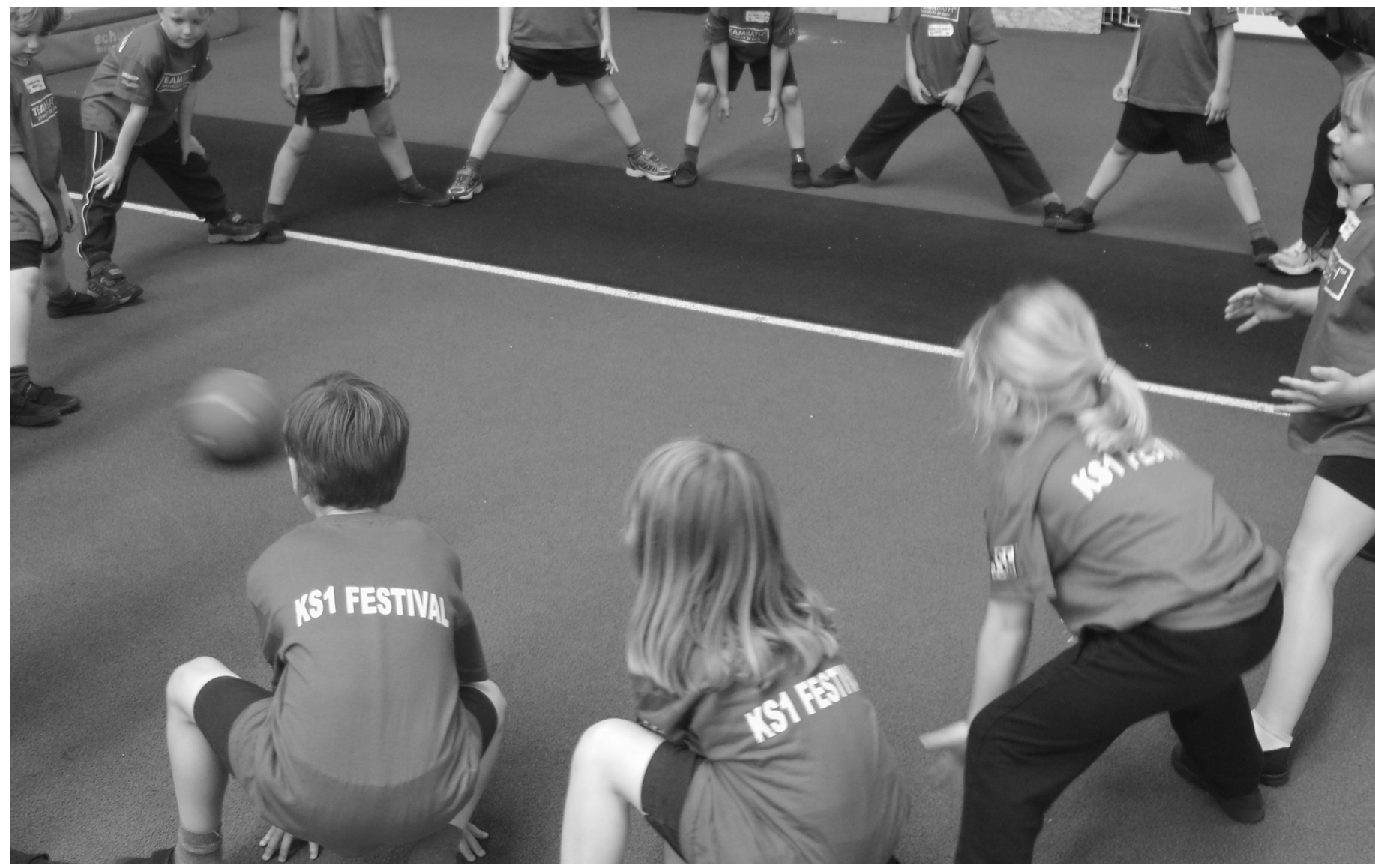




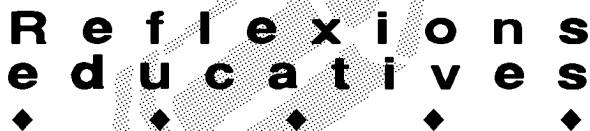

Taula 1. Relació de capacitats i habilitats d'acord a la competència comunicativa lingüística i audiovisual

\begin{tabular}{|c|c|}
\hline Capacitats & Habilitats \\
\hline $\begin{array}{l}\text { INTERACTUAR I DIALOGAR AM B } \\
\text { TOTHOM PER CONEIXER I } \\
\text { APROPAR-SE A ALTRES }\end{array}$ & $\begin{array}{l}\text { - Conèixer altres cultures. } \\
\text { - Generar diàleg. } \\
\text { - Incentivar la participació. } \\
\text { - Treballar la diversitat. } \\
\text { - Comunicar-nos amb l'entorn més proper. } \\
\text { - Desenvolupar les habilitats socials. } \\
\text { - Saber escoltar, saber esperar el torn de paraula, demanar ajuda. }\end{array}$ \\
\hline $\begin{array}{l}\text { CONSTRUIR UN PENSAM ENT } \\
\text { SOCIAL CRITIC EN EL } \\
\text { TRACTAM ENT DE LA } \\
\text { INFORM ACIÓ }\end{array}$ & $\begin{array}{l}\text { - Adquirir actituds crítiques. } \\
\text { - Realitzar crítiques constructives. } \\
\text { - Organitzar, recuperar, resumir i sintetitzar la informació. } \\
\text { - Conèixer les diferents tipologies textuals. } \\
\text { - Saber interpretar la informació. } \\
\text { - Saber comunicar les informacions. } \\
\text { - Cercar, seleccionar i processar la informació provinent de tot tipus de mitjans. }\end{array}$ \\
\hline $\begin{array}{l}\text { DOM INI DELS DIFERENTS } \\
\text { LLENGUATGES }\end{array}$ & $\begin{array}{l}\text { - Conèixer, treballar i aplicar els diferents llenguatges audiovisuals. } \\
\text { - Saber expressar-se amb els diferents llenguatges audiovisuals. } \\
\text {-Interpretar els diferents llenguatges audiovisuals. }\end{array}$ \\
\hline $\begin{array}{l}\text { MILLORAR LA COMUNICACIÓ } \\
\text { ORAL, ESCRITA, GESTUAL I } \\
\text { CORPORAL }\end{array}$ & $\begin{array}{l}\text { - Aprendre a parlar, escoltar, exposar i dialogar. } \\
\text { - Conèixer i interpretar diferents recursos comunicatius. } \\
\text { - Treballar de manera interdisciplinar aquesta comunicació. } \\
\text { - Utilitzar l'experimentació, escolta i moviment del cos com a instruments } \\
\text { d'expressió i comunicació. }\end{array}$ \\
\hline $\begin{array}{l}\text { UTILITZACIÓ DEL COSI DEL } \\
\text { M OVIM ENT COM A INSTRUM ENT } \\
\text { D'EXPRESSIÓ I COM UNICACIÓ }\end{array}$ & $\begin{array}{l}\text { - Saber interaccionar amb l'ús del llenguatge corporal. } \\
\text { - Expressar, entendre i interpretar la pròpia percepció del món. } \\
\text { - Utilitzar adequadament els recursos expressius de comunicació. }\end{array}$ \\
\hline $\begin{array}{l}\text { APRENDRE A TREBALLAR DE } \\
\text { M ANERA AUTONNOM A }\end{array}$ & $\begin{array}{l}\text { - Prendre decisions. } \\
\text { - Pensar projectes i dur-los a la pràctica. } \\
\text { - Autovalorar-se. } \\
\text { - Valorar possibilitats de millora. } \\
\text { - Proposar-se objectius i complir-los. }\end{array}$ \\
\hline $\begin{array}{l}\text { APRENDRE A TREBALLAR DE } \\
\text { M ANERA COOPERATIVA }\end{array}$ & $\begin{array}{l}\text { - Realitzar treballs en equip. } \\
\text { - Participar activament en la realització d'activitats cooperatives a l'aula. } \\
\text { - Posar-se en el lloc de l'altre. } \\
\text { - Valorar idees d'altres. } \\
\text { - Organitzar el temps i les tasques. } \\
\text { - Prendre el lideratge en activitats de grup. } \\
\text { - Ser flexible davant els canvis i les opinions. }\end{array}$ \\
\hline $\begin{array}{l}\text { DESENVOLUPAR LA CAPACITAT DE } \\
\text { RAONAR I UTILITZAR UN ESPERIT } \\
\text { CRITIC }\end{array}$ & $\begin{array}{l}\text { - Debatre. } \\
\text { - Solucionar conflictes i situacions problemàtiques. } \\
\text { - Reflexionar tot allò que es treballa. } \\
\text { - Dialogar. } \\
\text { - Ser conar. }\end{array}$ \\
\hline
\end{tabular}




\section{?.}

També és objectiu d'aquest article oferir algunes de les aportacions de l'àrea d'Educació Física a la competència comunicativa lingüística i audiovisual, d'acord amb el que hem presentat anteriorment (taula 2).

Taula 2. Aportacions de l'àrea d'Educació Física a la competència comunicativa lingüística i audiovisual

\section{A. INTERACTUAR I DIALOGAR AM B TOTHOM PER CONEIXER I APROPAR-SE A ALTRES CULTURES}

\section{A1. Conèixer altres cultures}

Apreciar el joc com a activitat comuna a totes les cultures.

Participar en la pràctica de jocs de tot el món.

Interactuar a través del propi cos.

A2. Generar diàleg. Incentivar la participació

Participar en situacions que impliquin la comunicació corporal i verbal, així com el reconeixement de les diferents formes d'expressar-se.

Expressar fets, conceptes, emocions, sentiments i idees a través del llenguatge corporal.

\section{A3. Treballar la diversitat}

Tenir disposició a participar en activitats diverses, acceptant les diferències individuals en l'habilitat motriu.

Valorar i acceptar la pròpia realitat corporal i la dels altres.

Tenir disposició per escoltar, observar i interpretar la informació que rep corporalment dels altres.

\section{A4. Comunicar-se amb l'entorn més pròxim}

Participar en situacions que provoquen la interacció entre l'espai i el temps.

\section{A5. Promoure el treball cooperatiu}

Participar en jocs cooperatius i per la pau.

Col·laborar activament en el desenvolupament dels jocs col/lectius mostrant responsabilitat i una actitud cooperativa.

\section{B. CONSTRUIR UN PENSAM ENT SOCIAL CRITIIC EN EL TRACTAM ENT DE LA INFORM ACIÓ}

\section{B1. Adquirir actituds crítiques. Realitzar crítiques constructives \\ Valorar críticament els recursos expressius i de comunicació del cos.}

B2. Organitzar, recuperar, resumir i sintetitzar la informació. Saber interpretar la informació. Saber comunicar

les informacions. Saber comunicar les construccions de coneixements més complexos

Detectar els aspectes essencials en el desenvolupament de les activitats físiques proposades.

Conèixer el propi cos per potenciar la comunicació corporal.

Saber expressar fets, conceptes, emocions, sentiments.

B3. Conèixer les diferents tipologies textuals

Treballar diferents tipologies aplicades a l'Educació Física.

B4. Buscar, seleccionar i processar la informació provinent de tot tipus de mitjans

Treballar la planificació d'activitats físiques utilitzant diferents recursos.

Expressar-se sobre els propis fets, sentiments i pensaments a través de l'expressió corporal.

$\mathrm{M}$ anifestar els diferents tipus de llenguatge corporal: mim, teatre, ombres xineses i dansa.

C. DOM INI DELS LLENGUATGES AUDIOVISUALS

C1. Conèixer, treballar, aplicar els diferents llenguatges audiovisuals

Aprendre a fer ús dels mitjans audiovisuals com a element d'autoavaluació dintre de les sessions d'educació física. 


\section{?.}

\section{C2. Saber expressar-se amb els diferents llenguatges audiovisuals. Interpretar els diferents llenguatges audiovisuals \\ Fer una anàlisi de la informació del món de l'educació física a través dels diferents llenguatges audiovisuals}

D. MILLORAR LA COM UNICACIÓ ORAL, ESCRITA, GESTUAL I CORPORAL

\section{D1. Aprendre a parlar, escoltar, expressar i dialogar}

Saber expressar-se i comunicar-se a través del llenguatge corporal.

Desinhibir-se en activitats comunicatives verbals i no verbals.

Utilitzar el cos i el moviment com instrument d'expressió i comunicació.

\section{D2. Conèixer i interpretar diferents recursos comunicatius}

Experimentar i escoltar el cos i el seu moviment, com a instruments d'expressió i comunicació.

\section{D3. Treballar de manera interdisciplinar la comunicació}

Conèixer i interpretar diferents recursos comunicatius.

Desinhibir-se en activitats comunicatives verbals i no verbals.

Valorar i gaudir de la comunicació en el grup.

Explorar sensorialment les possibilitats de moviment del cos.

Reconèixer, interpretar i representar corporalment elements musicals.

\section{D4. Experimentació, escolta i moviment del cos com a instruments d'expressió i comunicació}

Interaccionar amb l'ús del llenguatge corporal.

Saber expressar, entendre i interpretar la pròpia percepció del món.

Saber expressar fets, conceptes, emocions, sentiments a partir del gest.

Saber expressar-se a través del llenguatge corporal.

Descobrir les possibilitats expressives del cos a partir del joc dramàtic.

\section{E. UTILITZACIÓ DEL COSI DEL M OVIM ENT COM A INSTRUM ENT D’EXPRESSIÓ I COM UNICACIÓ}

\section{E1. Saber interaccionar amb l'ús del llenguatge corporal}

Saber expressar fets, conceptes, emocions, sentiments.

Expressar emocions i sentiments a través del cos, el gest i el moviment.

Utilitzar el propi cos per aprendre a comunicar-se amb la resta de companys i companyes.

Utilitzar els recursos expressius del cos per promoure el diàleg i el treball en grup.

\section{E2. Expressar, entendre i interpretar la pròpia percepció del món}

Saber expressar-se a través del llenguatge corporal.

Expressar i interpretar diferents tipus de discursos adequats a la situació comunicativa i en

diferents contextos socials i culturals.

Saber escoltar, observar i interpretar la informació rebuda per l'entorn.

Saber expressar emocions i sentiments respecte a la percepció que es rep de l'altre.

Les competències són un referent per a l'acció educativa $i$ ens informen sobre els aspectes que hem de fer que l'alumnat construeixi i, també, en conseqüència, són un referent per a l'avaluació, útil per comprovar el nivell assolit pels alumnes. Però les competències, com les capacitats, no són directament avaluables. Cal triar els continguts més adequats per treballar i desenvolupar, definir la seqüència i el graupropi dels diferents nivells i cursos, establint indicadors precisos assolits i encertar en les tasques que finalment es demanarà a l'alumne que realitzi.

\section{Conclusions}

La incorporació de les competències bàsiques suposa un enriquiment del model actual del currículum. Les competències bàsiques formen part dels ensenyaments 


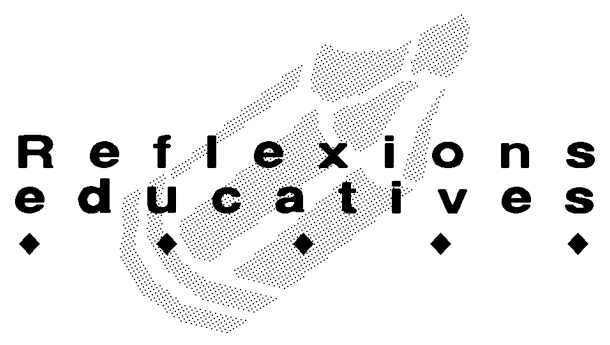

La principal contribució de les competències bàsiques consisteix a orientar l'ensenyament perquè permet identificar els continguts i els criteris d'avaluació. Hem volgut presentar un enfocament que faciliti el plantejament de la programació des de l'àrea d'Educació Física en relació amb els principis pedagògics de la LOE. Partint d'aquest compromís, presentem una proposta que pretén ser oberta i flexible a les necessitats particulars de cada centre educatiu d'acord amb les aportacions que ofereix l'Educació Física a la competència comunicativa lingüística i audiovisual.

Per això és imprescindible conèixer en profunditat cada una de les competències, així com les capacitats relacionades, les habilitats, les destreses...Tot aquest coneixement facilitarà al professorat la seva intervenció a l'aula i, conseqüentment, la transferència adequada de les competències al procés d'ensenyament i aprenentatge.

Valorant tota la proposta de seqüenciació respecte a les aportacions que pot oferir l'àrea d'Educació Física, podem dir que el desenvolupament de la competència comunicativa lingüística i audiovisual es veurà afavorida en un context cooperatiu de col·laboració i intercanvi amb els companys.

Aquest article només pretén ser un inici d'un llarg i minuciós camí a recórrer en què estem immersos tots els docents per portar a terme la nostra programació i establir un bon procés d'ensenyament i aprenentatge útil que respongui a les necessitats dels nostres alumnes.

\section{Referències}

Carreiro da Silva, F. (2009). "La gestión del currículo a través de competèncias: un enfoque desde elcontexto portugués", Tándem. Didàctica de la educación Física, 29, p. 8-9.

Coll, C. (2008). "Las competencias en la educación escolar: algo más que una moda y mucho menos que un remedio", Aula de Innovación Educativa, 161, p. 34-39.

Comisión Europea (2004). Competencias clave para un aprendizaje a lo largo de la vida. Un marco de referencia europeo. Puesta en práctica del programa de trabajo Educación y formación 2010. Grupo de trabajo B. Competencias Clave. Comisión Europea. Dirección General de Educación y cultura. Disponible en: . [Consulta: 16 d'abril de 2009].
Departament d'Ensenyament de la Generalitat de Catalunya. Disponible en: . [Consulta: 25 de febrer de 2009].

Edwards, D.; Mercer, N. (1994). El conocimiento compartido. El desarrollo de la comprensión en el aula. Barcelona: Paidós.

Fraile, A.; Hernández, J. L. (2006). “La formación del maestro de educación física en la encrucijada entre los marcos legislativos y las necesidades sociales". Aula de Innovación educativa, 157, p. 65-71.

Freire, P. (1998). Pedagogía de la autonomía: saberes necesarios para la practica educativa. M èxic D. F: Siglo XXI editores.

Jiménez, J.R. (2007). “Competencias básicas". Redes, 1, 1.

Latorre, A.; Del Rincón, D.; Arnal, J. (1996). Bases metodológicas de la investigación educativa. Barcelona: Hurtado Ediciones. M inisteri d'Educación i Ciència. Reial decret 1513/2006 de desembre, pel qual s'estableixen les ensenyances mínimes de l'educació primària. BOE n. 293, de 8 dedesembre de 2006.

Pacte Nacional per a l'Educació. Debat curricular (2003). Generalitat de Catalunya. Departament d'educació. p. 118.

Parlamento Europeo y Consejo de la Unión Europea (2006). Recomanació del Parlament Europeiu i del Consll del 18 de desembre de 2006 sobre les competències clau per a l'aprenentatge permanent. Diario Oficial de la Unión europea. L394/10-18. 30 de desembre de 2006.

Reial Decret 1513/2006 de 7 de desembre, pel qual s'estableixen els ensenyaments de l'educació primària.

Ruíz Pérez, L. M . (2004). “Competencia motriz, problemas de coordinación y deporte", Revista de educación, 335, p. 21-23.

Stake, R. E. (1999). Investigación con estudio de casos. M adrid: M orata.

Sebastià, S. (1996). Cap a una lògica de la seducció. Barcelona: EUB. 